\title{
Artigos
}

\section{Processo de Drama na Educação Infantil: uma análise a partir das estratégias Professor- personagem e Professor em ação dramática}

\begin{abstract}
Resumo: O artigo apresenta uma reflexão acerca de um processo de Drama na Educação Infantil, realizado com crianças em idade pré-escolar em um Centro Municipal de Educação Infantil (CMEI), na cidade de Curitiba/PR. O processo dramático analisado ocorreu a partir de duas estratégias empregadas na atuação artística de um dos pesquisadores com as crianças: Professor-personagem e Professor em ação dramática. As propostas utilizadas de forma simultânea contribuíram para uma efetiva comunicação entre crianças e professor/pesquisador, momento em que ambos se tornaram autores e condutores do processo dramático.
\end{abstract}

Palavras-chave: Drama. Educação Infantil. Professor-personagem. Professor em ação dramática.

\section{Process Drama in Early Childhood Education: an analysis based on Teacher-in-role and Teacher in dramatic action strategies}

Abstract: The article presents a reflection about a process of Drama in Childhood Education, carried out with children of preschool age in a Municipal Center of Early Childhood Education (CMEI), in the city of Curitiba/PR. The dramatic process analyzed was based on two strategies employed in the artistic performance of the researcher with the children: Teacher-in-role and Teacher in dramatic action. The proposals used simultaneously contributed to an effective communication between children and teacher/researcher, when both became authors and drivers of the dramatic process.

Keywords: Drama. Early Childhood Education. Teacher-in-role. Teacher in dramatic action.

\footnotetext{
' Doutor em Artes da Cena pela Universidade Estadual de Campinas. Professor Adjunto na Universidade Estadual do Paraná. Email:rossetorobson@gmail.com

2 Graduada em Licenciatura em Teatro pela Universidade Estadual do Paraná. E-mail:melaine.pilatto@hotmail.com
} 
"Tu te tornas eternamente responsável por aquilo que cativas" (Saint-Exupéry2015, p.74) ${ }^{3}$

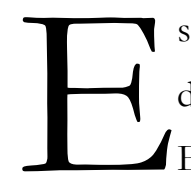

ste artigo tem como objetivo refletir o Drama na Educação Infantil a partir de um processo dramático desenvolvido com crianças em idade pré-escolar em um Centro Municipal de Educação Infantil na cidade de Curitiba/PR. As estratégias Professor-personagem e Professor em ação dramática fundamentaram as experiências criativas empreendidas pelas crianças. A pesquisa se constitui numa investigação teórico-prática, acerca do papel do professor no desenvolvimento de atividades dramáticas na Educação Infantil. Como base teórica, o texto apresenta as investigações de autores ingleses sobre a metodologia do Drama, associados com os estudos de pesquisadores brasileiros com relação ao tema, sobretudo Beatriz Cabral (2012) e Elisângela Pinheiro Leite (2015). A partir dos experimentos realizados com crianças pequenas (4 anos a 5 anos e 11 meses), foi possível refletir a respeito da atuação artística do professor no trabalho pedagógico dramático desenvolvido com crianças.

$\mathrm{O}$ interesse em realizar esta pesquisa surge da necessidade de se refletir sobre a expressão dramática na Educação Infantil, dado que as investigações nessa área específica do conhecimento têm história recente no Brasil, ou seja é um campo de conhecimento ainda em constituição. O contato inicial com a temática ocorreu em 2014, por um dos pesquisadores deste artigo, em um curso de extensão intitulado "Teatro com crianças pequenas: Construção de Sentido na Práxis Pedagógica", promovido pela Universidade Estadual do Paraná - UNESPAR e ministrado por Elisângela Leite.

A epígrafe que inicia este trabalho, de Antoine de Saint-Exupéry, evidencia a responsabilidade do encantamento efetivado nas distintas relações humanas e, por esta razão, a referida frase expressa a suma relevância das experiências ligadas à sensibilidade. Diariamente estabelecemos relações significativas no mundo enquanto sujeitos, seja em nosso trabalho, em nossa família ou nas demais convivências sociais. Estas relações se estabelecem através do envolvimento, sedução e empolgação, características que dialogam com a ação de cativar, fundamentais para o desenvolvimento da expressão dramática na Educação Infantil, com crianças pequenas. No entanto, o teatro por definição é

[...] a arte de parecer, de exprimir a realidade representando-a, de a dar a conhecer dizendo-a, a arte de mostrar a vida sem a viver, tendo, em comparação com as outras formas de arte, a particularidade de serem seres humanos que, por um instante, encarnam de um modo sensível e vivo outros seres humanos cuja existência é apenas imaginária (LEENHARDT, 1974, p. 13).

O adulto enquanto ator possui a capacidade imaginária de desempenhar papéis e de atuar formalmente no que se define por teatro. Porém, de acordo com Leenhardt (1974), ao referir-se a infância

\footnotetext{
3 Obra "Pequeno Príncipe" de Antoine de Saint-Exupéry.

${ }_{4}$ O curso teórico-prático foi organizado em 10 encontros que aconteceram durante os meses de marco a junho de 2014 , com base nos seguintes conteúdos: jogos dramáticos, faz de conta infantil, elementos cênicos, formas animadas, teatro para e com bebês, professor em ação dramática e formação de professores de crianças pequenas. Para a finalização do curso, os participantes em duplas elaboraram uma oficina para formação de professores de crianças pequenas que abordasse um dos conteúdos estudados ao longo do curso.
} 
prefere-se evitar falar de representação teatral, preferindo-se a designação de jogos dramáticos ou expressão dramática, buscando explorar o imaginário como meio de expressão privilegiada da criança.

Sendo assim, a criança em um processo de dramatização, recorre a sua imaginação por meio do lúdico, no qual envolve o pensamento e a fala, na elaboração de histórias improvisadas. No âmbito da educação, é uma atividade que visa a aprendizagem e o desenvolvimento por meio das vivências de situações cotidianas e fantasiosas, e de forma coletiva, a criança brinca, imagina, deseja, observa, experimenta, questiona, processo este que colabora na construção da sua identidade pessoal.

Ao considerar as especificidades da criança, cabe ressaltar a importância da motivação da imaginação nesta fase e a preocupação em dar ênfase ao processo dramático ao invés do resultado. Diante dessa concepção, o Drama foi selecionado como metodologia a ser investigada e aplicada nesta pesquisa. Os estudos do Drama como atividade de ensino no Brasil, teve início no ano de 1978 com a publicação do livro "O jogo dramático infantil", tradução de Child dramade 1954, do pesquisador inglês Peter Slade.

Nesta obra, o autor apresenta um método de treinamento emocional planejado, baseado em trinta anos de observação de crianças jogando. Ao longo da sua investigação, Slade (1978) relaciona o jogo com a vida, quando constata que o jogo dramático é uma parte vital da vida da criança, uma vez que ela pensa, comprova, relaxa, trabalha, lembra, ousa, cria e absorve, ao longo das experiências dramáticas. O autor afirma que o "Jogo dramático Infantil é uma forma de arte por direito próprio; não é uma atividade inventada por algúem, mas sim o comportamento real dos seres humanos" (SLADE, 1978, p. 17).

O jogo dramático no contexto educacional requer uma ação diferenciada do professor, dado o papel fundamental dele como condutor/mediador dos processos dramáticos, cabendo destacar as seguintes ações:

Ao professor, 'aliado amoroso', 'guia bondoso e suave', cabe uma atuação peculiar. Ele suscita a manifestação lúdica, faz perguntas relativas ao jogo, conta histórias a serem dramatizadas, atribui papéis, propõe situações fictícias, solicita contribuições dos jogadores, chama a atenção para detalhes da dramatização, joga junto com o grupo. É sempre ele o fio condutor da experiência; sua tutela se manifesta não só pela voz; até mesmo a integridade da sua pessoa pode se fazer presente e mesclar-se à ficção gerada (PUPO, 2005, p. 222).

No Brasil, a pesquisadora Beatriz Cabral nos anos de 1990 iniciou investigações do Drama como método de ensino, com crianças da Educação Básica. A proposta do Drama se caracteriza como um método sistematizado com características próprias, tais como: o desenvolvimento cênico ocorre com base em um contexto de circunstância e ficção, em que o pré-texto atua como potencializador na construção da narrativa teatral em grupo, cujo processo transcorre através de episódios. Nesse contexto, o professor atua como mediador por meio da estratégia do Professor-personagem. De acordo com a autora:

O drama como método de ensino, eixo curricular e/ou tema gerador constitui-se atualmente numa subárea do fazer teatral e está baseado num processo contínuo de exploração de formas e conteúdos relacionados com um determinado foco de investigação (selecionado pelo professor ou negociado entre professor e aluno). Como processo, o drama articula uma série de episódios, os quais são construídos e definidos com base em convenções teatrais criadas para possibilitar seu sequenciamento e aprofundamento (CABRAL, 2012, p.12). 
Desse modo, o desenvolvimento do Drama se dá a partir de espisódios que são impulsionados por um pré-texto que delimita o tema gerador juntamente com a atuação docente como Professorpersonagem. Cabe destacar que,

A expressão 'professor-personagem' foi a tradução escolhida para a convenção inglesa 'teacher in role', justificando-se tanto pela impossibilidade de uma tradução literal, quanto pelas características que o uso desta estratégia foi adquirindo no contexto brasileiro. Ao assumir um personagem, o professor de imediato obtém a atenção da turma mediante o impacto visual causado (figurino e cenário podem apoiar os personagens assumidos pelo professor), e amplia suas possibilidades de introduzir desafios e/ou informações necessárias ao processo coletivo (CABRAL, 2012, p. 19).

O Professor-personagem "assume papéis e/ ou personagens com o objetivo de interagir com os alunos em contextos diversos, utilizando diferentes códigos linguísticos para desafiar posturas, ações e atitudes."(CABRAL, 2012, 19). A atuação do Professor-personagem está associada com o pré-texto, o roteiro, a história ou o texto que fornecerá o ponto de partida para iniciar o processo dramático, e que irá funcionar como pano de fundo para orientar a seleção e identificação das atividades e situações exploradas cenicamente.

Outra estratégia, especialmente vinculada ao drama na Educação Infantil é o Professor em ação dramática, proposta elaborada por Leite (2015), assim definido pela autora: "Professor em ação dramática é uma prática preconizada a partir do uso do drama, desta forma, o professor utiliza suas expressividades para facilitar a comunicação com as crianças da Educação Infantil” (2015, p. 41004, grifos do autor).

Leite $(2017)^{5}$ relata que o seu estudo acerca da estratégia Professor em ação dramática foi inspirado no trabalho desenvolvido pela pesquisadora Beatriz Cabral, sem a pretensão de estabelcer um comparativo com a estratégia do Professor-personagem, com o objetivo de ser uma proposta complementar aos estudos do Drama. A pesquisadora acrescenta que um dos motivos que impulsionaram a sua pesquisa foi a perceção que tanto a estratégia Professor em ação dramática quanto Professor no papel $^{6}$ não foram pensadas para o contexto da Educação Infantil. Nessa perspectiva, a proposta foi estudada com professores que atuam na Educação Infantil, e em sua maioria não possuem formação em teatro ou de ator/atriz. De acordo com a autora, as proposições do Professor em ação dramática estão relacionadas com a profissionalidade ${ }^{7}$ da Educação Infantil, no qual o docente se utiliza de recursos dramáticos para potencializar a comunicação entre o professor e as crianças pequenas.

A pesquisa foi fundamentada nos referidos autores, e se propôs a investigar as duas estratégias, Professor-Personagem e Professor em ação dramática nas ações empreendidas com as crianças pequenas. A investigação foi realizada através da prática desenvolvida em um Centro Municipal de Educação Infantil, na cidade de Curitiba, no ano de 2017, com uma turma matriculada no Pré II, formada por 30 crianças, de faixa etária entre 4 a 5 anos de idade.

\footnotetext{
${ }^{5}$ Entrevista concedida por Elisângela Leite no dia quatro de setembro do ano de 2017 na cidade de Curitiba.

6 Professor no papel é uma das possibilidades que o professor-artista possui para trabalhar em sala de aula. De acordo com Heloise Baurich Vidor (2010), o termo está associado principalmente à possibilidade de assumir papéis sociais, na intervenção pedagógica.

7 O termo profissionalidade, segundo Sacristán(1999), se refere ao conjunto de comportamentos, conhecimentos, atitudes e valores que constituem a especificidade de ser professor.
} 
Cabe destacar, para o desenvolvimento de uma proposta criativa com crianças da Educação Infantil, é imprescindível efetivar relações. De acordo com Leite (2015) o processo relacional que se constrói, de maneira gradativa, ocorre por meio das ações do professor que trabalha com crianças pequenas, sendo assim, “A Educação Infantil é feita de sutilezas, essas sutilezas se fazem no exercicío de observação e ação diante do que é necessário no espaço e na relação com elas” (LEITE, 2015, p. 31).

Com base nesse princípio, a pesquisa foi organizada em três observações participativas, e dois encontros práticos que ocorreram em semanas consecutivas, onde o processo drama foi desenvolvido. A observação participativa é aquela em que o pesquisador opta por partilhar o momento da observação sempre que as circunstâncias permitam, realizada com o objetivo de investigar as ações do professor na Educação Infantil. Além disto, a observação participativa proporcionou um espaço para conhecer as crianças e possibilitou a criação de um vínculo afetivo com elas, fator importante no relacionamento professor e crianças, especialmente na educação infantil (FIGURA 1). Nesse sentido "É preciso construir a confiança por meio da amizade e criar a atmosfera propícia por meio da consideração e empatia" (SLADE, 1978, p. 18).

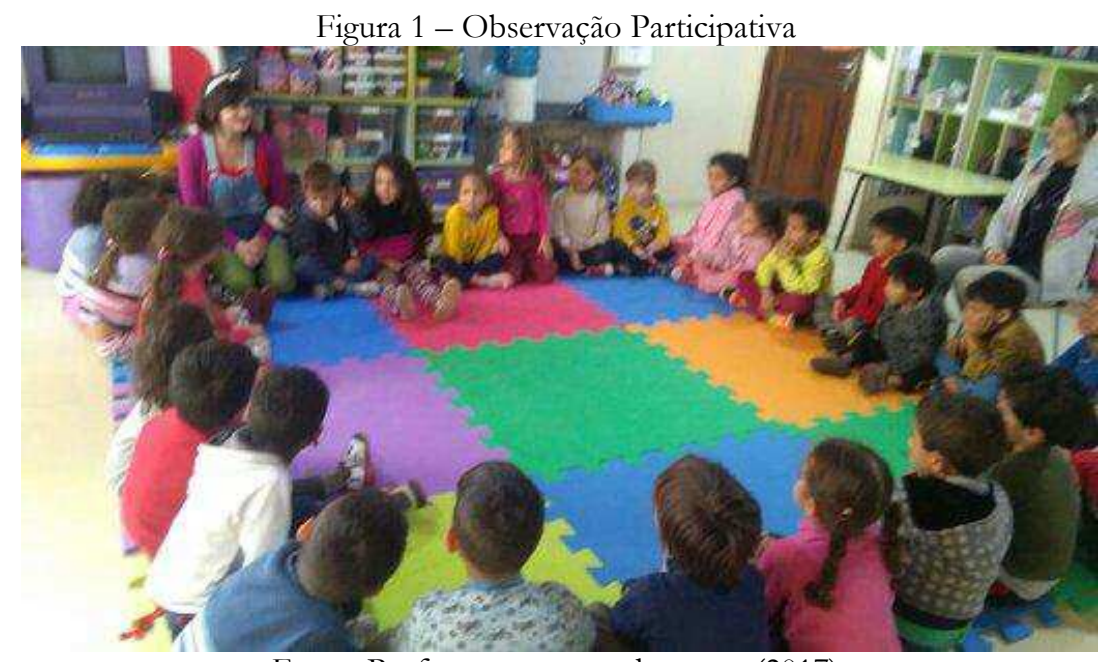

Fonte: Professora regente da turma (2017)

A observação participativa também teve o objetivo de pesquisar os variados estímulos que pudessem ser inseridos durante o processo dramático e contribuiu para o planejamento da proposta, além de influenciar na escolha da personagem, utilizada na estratégia do Professor-personagem. Na relação estabelecida com as crianças durante a observação participativa busquei ter um olhar cuidadoso e sensível com elas, que se estendeu durante toda a pesquisa. Nos momentos de interação com os pequenos, percebi $^{8}$ nas minhas ações vestígios da minha palhaça, que enquanto artista venho desenvolvendo nos últimos anos. Por esta razão, resolvi utilizar esta personagem como Professora-personagem, na condução do processo dramático, desenvolvido junto com as crianças.

8 O desenvolvimento prático da pesquisa foi realizado por um dos pesquisadores deste artigo, cuja investigação subsidiou a elaboração do Trabalho de Conclusão do Curso - TCC do Curso de Licenciatura em Teatro da Universidade Estadual do Paraná, campus de Curitiba II. 
Para dimensionar o potencial da minha Palhaça como Professora-personagem, recorremos aos estudos de Cabral (2012), quando afirma que os tipos de papéis representados pelo professor podem ser classificados quanto a sua função e seu status, uma vez que "o papel assumido pelo professor pode ser metaforicamente representado como o de um obstáculo, o qual os alunos precisam superar através do argumento, da negociação ou do compromisso.” (CABRAL, 2006, p. 20). É importante que o status da personagem do professor seja menor que o status da personagem da criança, pois assim, a relação entre as crianças/personagens com o professor personagem durante o processo dramático poderá ocorrer de forma mais espontânea, na medida em que rompe com qualquer hierarquia dentro do espaço escolar. No entanto, se o professor assumir um papel com o status mais alto em relação ao papel atribuído ao estudante, ele deterá o controle do processo, podendo impedir o desenvolvimento da autonomia daquele. De qualquer modo, caso haja indisciplina e/ou outros problemas de concentração para o desencadeamento cênico, um status alto para a personagem do professor poderá ser a melhor opção para controlar e conduzir com mais eficiência o processo dramático.

Cabral apresenta possibilidades sobre as funções que o professor-personagem pode asumir durante um processo drama, entre elas estão: buscar auxílio ou conselho; buscar informações; coordenar, desafiar e/ ou introduzir. Quanto ao status, alto, intermediário e baixo, a escolha de um ou outro dependerá dos participantes envolvidos com o qual se está trabalhando, de acordo com os objetivos e o desenvolvimento das ações. Cabe destacar alguns exemplos citados pela pesquisadora: "Status alto: rei, capitão, líder, treinador, diretor de escola, etc. Status intermediário: secretário, representante de alguma autoridade, membro da comunidade ou da tripulação, etc. Status baixo: pedinte, vítima, refugiado, aprendiz, etc" (CABRAL, 2006, p. 21)

Dentre as atribuições mencionadas pela autora, a personagem Palhaça tinha a função de buscar auxilio, tendo assim um status baixo, pois necessitava de ajuda para encontrar seu nariz, com o intuito de conseguir voltar para a sua casa, narrativa elaborada para iniciar o processo dramático. Diante dessa circunstância, "Com um status baixo, o professor dependerá da boa vontade e da iniciativa da classe" (CABRAL, 2012, p. 22). Nesse contexto "A melhor brincadeira teatral infantil só tem lugar onde oportunidade e encorajamento lhe são conscientemente oferecidos por uma mente adulta. Isto é um processo de nutrição e não é o mesmo que interferência” (SLADE, 1978, p. 18).

O pré-texto, elemento que serve como ponto de partida ao processo Drama foi selecionado de acordo com o planejamento da turma. Em conversa com as duas professoras regentes, identifiquei que elas estavam trabalhando com as crianças a literatura infantil "O Pequeno Príncipe" de Antoine de SaintExupér, no qual já tinham sido realizadas atividades e ainda estavam previstas outras ações relacionadas com a obra no planejamento para acontecerem ao longo do ano letivo de 2017.

A partir do universo da referida história foram retirados elementos que funcionaram como estímulos para o processo Drama. Para a investigação dos estímulos utilizei a teoria dos Indutores, proposta desenvolvida por Jean-Claude Landier e Giséle Barret (1994), classificados da seguinte forma: objeto, imagem, som, personagem e texto. Segundo os pesquisadores, os indutores são mais que 
mediadores, instrumentos ou auxiliadores, o indutor serve de via de acesso (LANDIER; BARRET, 1994, p. 21). Leite (2015) acrescenta que:

Os indutores da ação dramática: objeto, imagem, som, personagem e texto, são ativos mobilizadores da reação das crianças, tornando o processo da ação educativa rica de experiências. Não há obviamente necessidade de uso de todos os indutores numa mesma proposta, mas eles inegavelmente são mobilizadores da ação das crianças. Geram experiências que condizem com um aprendizado vivo, dentro do contexto da Educação Infantil (LEITE, 2015, p. 41014).

O primeiro indutor utilizado foi um texto elaborado para introduzir o pré-texto no espaço escolar. Este indutor foi uma carta destinada as crianças da turma do pré II, com o objetivo de iniciar o processo dramático. A escrita continha a seguinte redação:

Olá, há um tempo eu e um amigo decidimos fazer uma viajem pelos planetas, passamos por vários planetas até chegar ao Planeta Terra, porém, agora tenho um problema, meu amigo já conseguiu voltar ao seu Planeta de origem e eu fiquei aqui perdida, pois nesta viagem perdi o meu nariz, e sem ele não consigo voltar para o meu planeta. Eu preciso de ajuda para recuperar o meu nariz, e foi por isso que resolvi escolher um grupo para embarcar comigo nesta aventura. Eu andei observando vocês e percebi que podem ser um ótimo grupo! Vocês querem me ajudar? Se toparem, por favor, preciso que cada um de vocês me deem uma reposta, através de uma carta me respondam se querem embarcar nesta aventura ou não. Esta carta poderá ser feita por meio de desenhos e seria muito legal se vocês assinassem com a inicial de seus nomes.

Segue o meu endereço onde estou alojada temporariamente:

Avenida Do Atântico Sul, 123456.

Assinado: A palhacinha que perdeu seu nariz.

A carta buscou apresentar a personagem no ambiente pedagógico, além de introduzir o pré-texto, trazendo consigo o problema a ser solucionado. Cabe destacar, que esse recurso também serviu como veículo de comunicação entre as crianças e a personagem. A partir da leitura da carta, realizada por uma das professoras regentes ${ }^{9}$, as crianças foram mobilizadas a responder a palhaça através de desenhos para expressarem se gostariam ou não de participar da "aventura", metáfora usada para a autorização da participação no processo Drama (FIGURA 2). A proposta das crianças autorizarem suas participações, foi pensada a partir do princípio da autonomia, fundamento ético a ser desenvolvido na Educação Infantil segundo as Diretrizes Curriculares Nacionais para a Educação Infantil (BRASIL, 2010).

Figura 2 - Desenhos elaborados pelas crianças

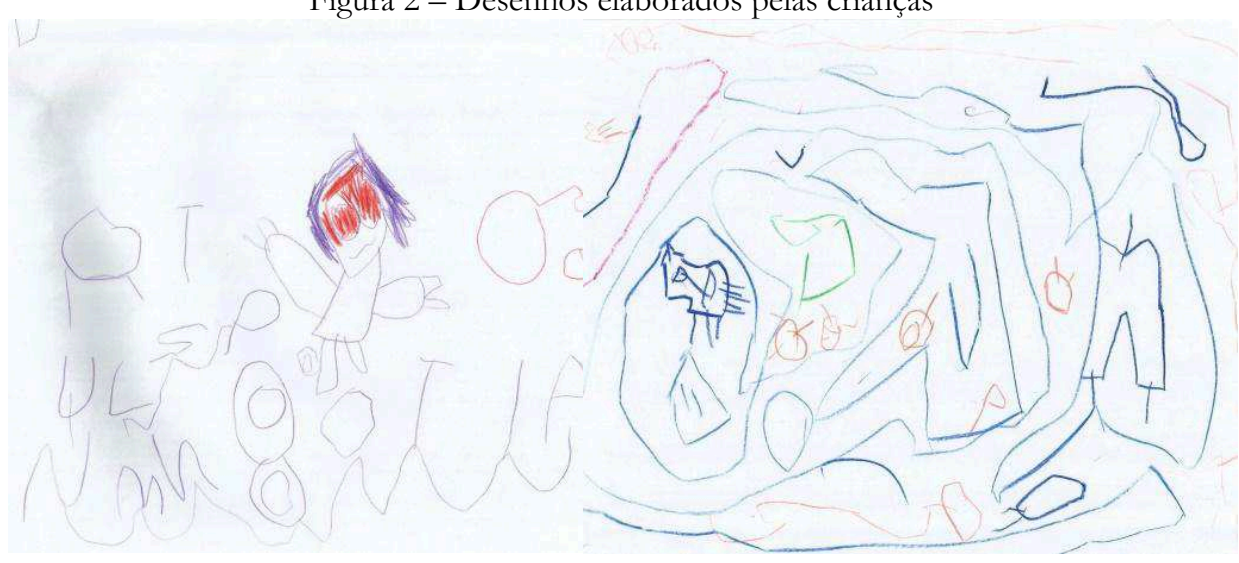

Fonte: Crianças do pré II (2017)

\footnotetext{
9 Duas professoras regentes graduadas em Pedagogia coordenam o trabalho pedagógico diário com as crianças. A pesquisa foi realizada com a presença delas em sala de aula, e juntos acordamos que elas poderiam interferir e colaborar na organização da turma e nas atividades propostas quando fosse necessário.
} 
Na prática analisada foram utilizados os seguintes indutores: texto, objeto, som e personagem, empregados nesta ordem. $\mathrm{O}$ indutor texto foi a carta, transcrita acima. Os indutores-objetos utilizados ao longo da prática foram os seguintes: tules e estrelas no primeiro encontro e lanternas e uma mala, no segundo encontro. Os tules foram deixados no chão, disponíveis para a manipulação das crianças, em que requereu delas a descoberta de funcionalidades (FIGURA 3). Conforme a imagem, as crianças criaram uma espécie de carruagem, onde os tules serviram como um cordão de delimitação da carruagem. Desta forma, quem estivesse dentro do cordão criado com os tules estavam dentro do vagão. A partir dos tules outras ideias foram sugeridas pelas crianças, tais como: "É uma rede!", outra criança complementou, "É uma rede para pegar o vilão".

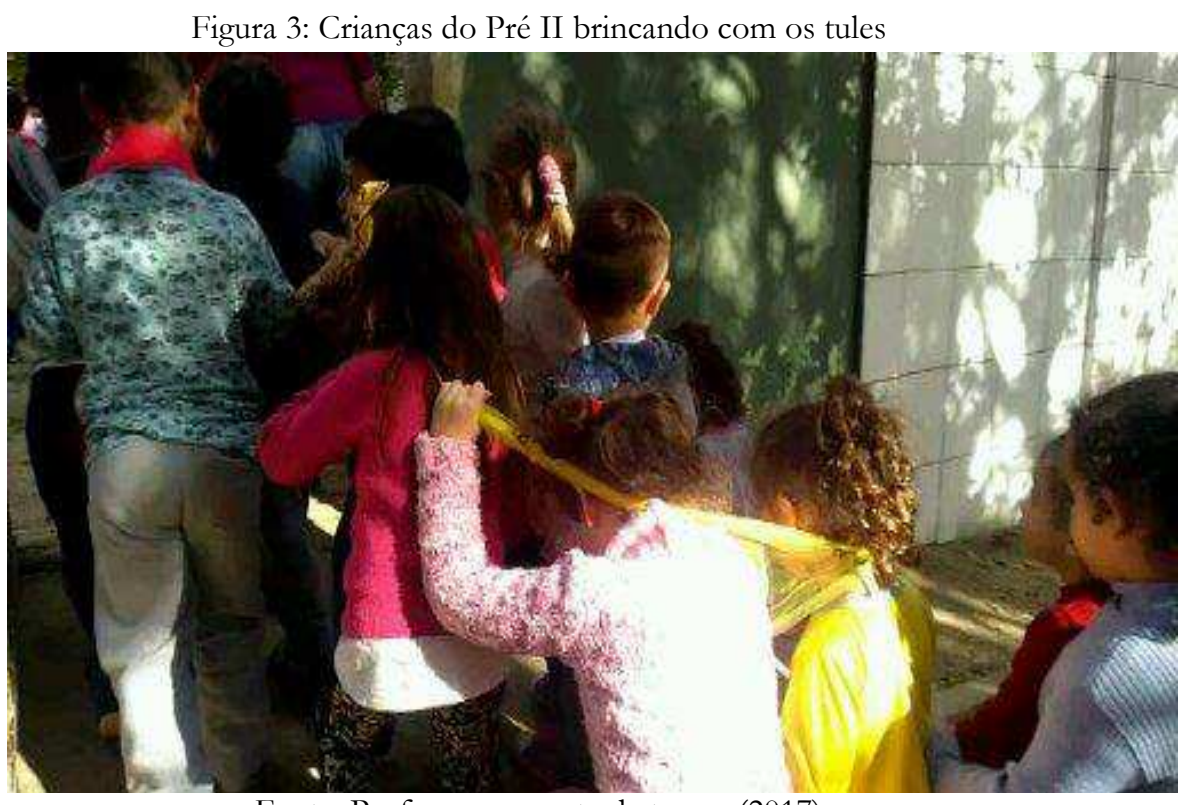

Fonte: Professora regente da turma (2017)

O som como indutor foi utilizado nas músicas e no áudio gravado com a fala do personagem Rei, presente na história do Pequeno Príncipe. As cantigas populares, "Cravo e a Rosa", "Boi da cara preta" e o "Sapo não lava o pé", foram levadas no primeiro encontro para que as crianças dançassem com o intuito de mobilizar a disponibilidade corporal. Cabe destacar: "Com a utilização do indutor sonoro, trata-se, pela escuta de diversos sons, de músicas, de canções, de fundos sonoros, de suscitar o movimento, o pôr em acção dos corpos e de permitir a produção espontânea do imaginário" (LAINDER e GISELE, 1999, p. $51)$.

De fato, a sonoridade instigou a curiosidade das crianças, que ao escutarem a voz do personagem Rei, elas prestaram atenção e fizeram perguntas sobre quem era aquela pessoa que mandou o recado, por exemplo: "É o Pequeno Príncipe?" e "É algum amigo seu Palhaço?". No entanto, em nenhum momento elas relacionaram a voz com o personagem Rei. A partir da solicitação do áudio, fomos procurar pelo personagem Vaidoso em distintos locais. As crianças estavam tão imersas no faz de conta que quando 
encontraram uma pessoa que não fazia parte da realidade escolar, pediram para saírem a rua. Nesse momento, as crianças curiosas, perguntaram se esta pessoa era o Vaidoso, quando a mesma respondeu de forma negativa. Com base nessa experiência, recorro aos estudos de Cortney, quando afirma que:“A imaginação criativa é essencialmente dramática em sua natureza. É a habilidade para perceber as possibiliades imaginativas, compreender as relações entre dois conceitos e captar a força dinâmica entre eles" (CORTNEY, 2003, p. 3.).

O personagem Vaidoso era um boneco de luva e estava escondido em uma casinha de madeira. Ao ser encontrado pelas crianças, assumi a manipulação do boneco. $O$ boneco foi um indutor personagem e atuou desde o início como um personagem de negociação. Logo que este personagem apareceu, as crianças criaram um forte vínculo com o boneco Vaidoso, proporcionando um papel de destaque nas ações, atuando junto com a professora-personagem como condutor do processo em desenvolvimento (FIGURA 4).

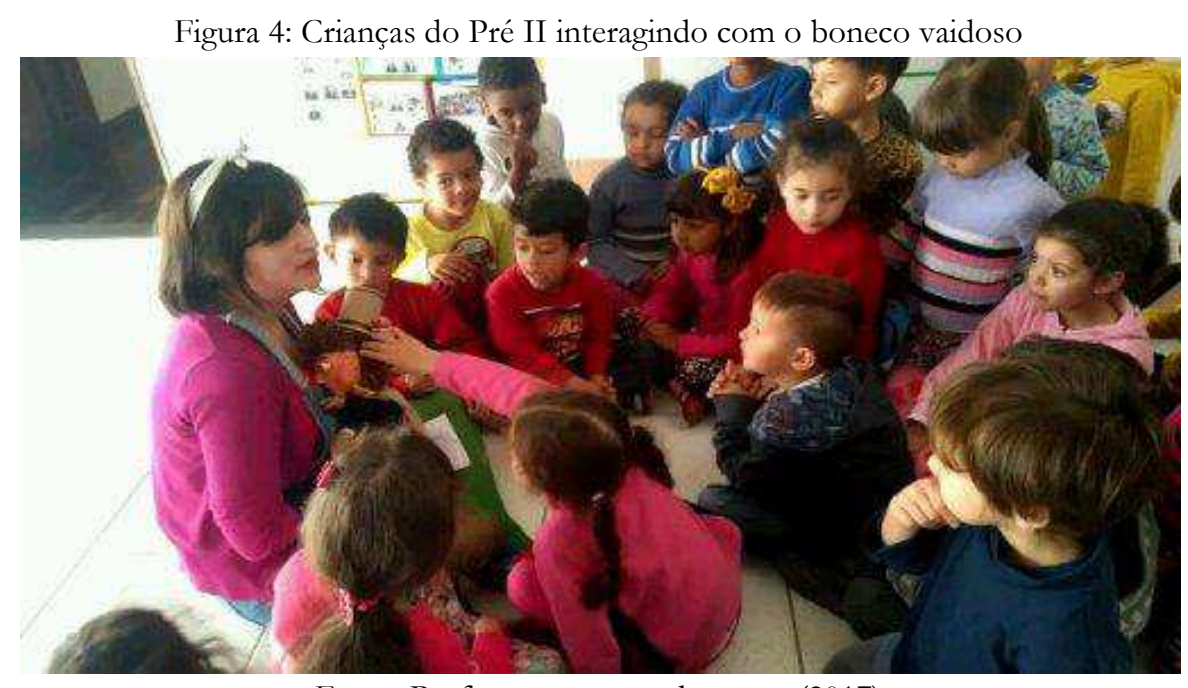

Fonte: Professora regente da turma (2017)

"O que é importante nos jogos com bonecos é a posibilidade que a criança tem de se imaginar na realidade, logo de permanecer no imaginário"(LENHARDT, 1973, p. 51). Nesse sentido, o boneco provocou uma intensa interação, atraiu e seduziu o imaginário infantil. $O$ personagem Vaidoso foi manipulado por mim e tinha como objetivo fornecer informações sobre onde estaria o nariz, porém, ao encontrar o Vaidoso, não encontramos o nariz. Ele nos sugeriu que procurassemos o Homem de Negócios, quando entregou um envelope de papel que deveria conter 10 estrelas, para negociarcom o mesmo, informações e/ou o próprio nariz. Para a surpresa do grupo, o pacote continha apenas uma estrela, as demais estavam perdidas e deveriam ser encontradas para um encontro com o Homem de Negócios. O episódio finalizou sem termos achado todas as estrelas.

No segundo encontro utilizei como indutores os personagensVaidoso e o Homem de Negócios, outro boneco de luva que estava dentro de uma mala. Para a abertura da mala ouvimos um novo áudio, no qual solicitava/relembrava a busca das 9 estrelas e mais um desafio: naquele dia cada criança deveria imitar 
um animal, enquanto cassavam as demais estrelas perdidas. Lembramos que no último encontro, tínhamos achado apenas sete das dez estrelas, a palhaça interferiu dizendo que tinha encontrado uma estrela no caminho de casa e perguntou para as crianças se elas também teriam encontrado as outras estrelas. Uma criança respondeu: "Eu procurei na minha casa, mas não encontrei".

Em seguida, a palhaça sugeriu que o grupo procurasse pela sala as estrelas faltantes. Para este desafio, foram entregues as lanternas que se constituíram como objetos indutores. As cortinas da sala foram fechadas, deitamos no chão com os olhos fechados, contamos até dez para começar a caça. As crianças exploraram os cantos do espaço e também as possibilidades das luzes, momento em que formaram naturalmente pequenos grupos e brincaram com as lanternas.

Quanto a tarefa de imitar animais, a professora regente percebeu que as crianças estavam com dificuldades para escolher um animal. Na tentativa de realizar a atividade, ela sugeriu para cada criança, ao pé do ouvido, um animal para ser imitado. No intuito de contribuir com a atividade acabou-se realizando uma separação entre fazedores e espectadores, plateia e palco, o que inibiu o processo criativo das crianças. O Drama, de acordo com Slade (1978), se diferencia do Teatro pelo fato de não haver este distanciamento entre atores e público. No Drama todos são fazedores podendo ir para qualquer direção durante o jogo.

Após encontrarmos as estrelas faltantes e de termos explorado corporalmente ações de alguns animais conseguimos abrir a mala e lá estava o Homem de Negócios, outro boneco de luva manipulado por mim. O personagem interagiu com as crianças parabenizando-as por terem trabalhado em grupo e por terem cumprido todas as tarefas solicitadas. Além disso, ele afirmou que o nariz da palhaça estava onde eles tinham cultivado algo importante da história do Pequeno Príncipe. De forma rápida, um garoto respondeu: "Eu sei! Lá na rosa que plantamos". Imediatamente, como professora-personagem conduzi a turma até o local onde eles tinham plantado a rosa, momento em que encontramos o nariz da palhaça. Em seguida, com entusiasmo, as crianças tocaram e experimentaram o nariz, ocasião em que a palhaça finalmente colocou o seu nariz. As crianças demonstraram muita empolgação e sentimento de dever cumprido. Ao mesmo tempo, percebi uma certa melancolia, pois sabiam que a palhaça voltaria para a sua casa. Antes da despedida, a palhaça solicitou para as crianças a elaboração de um desenho como recordação. Após a tarefa cumprida, algumas vieram ao seu encontro para abraça-la.

A pesquisa relatada contribuiu sobremaneira para a minha formação enquanto artista-professora, especialmente pela profícua experiência com a expressão dramática na Educação Infantil. As situações vivenciadas indicam que as crianças se empenham em extrair um sentido mais profundo de seus experimentos pessoais, fazendo com que uma experiência individual se torne uma experiência coletiva. Por esta razão,

A ideia de formação não se entende teologicamente em função de seu fim, em termos do estado final que seria sua culminação. O processo da formação está pensado, melhor dizendo, como uma aventura. E uma aventura é, justamente, uma viagem no não planejado e não traçado antecipadamente, uma viagem aberta em que pode acontecer qualquer coisa, e na qual não se sabe onde se vai chegar, nem mesmo se vai chegar a algum lugar (LARROSA, 2004, p. 52-53). 
"A formação é uma viagem aberta, uma viagem que não pode estar antecipada, e uma viagem interior, uma viagem na qual alguém se deixa influenciar por si próprio" (LARROSA, 2004, p. 53). As ações empreendidas pela Palhaça junto com as crianças foram planejadas através de um roteiro de proposições e a dramaticidade ocorreu por meio da interação e da imaginação delas, processo formativo compreendido metaforicamente como uma viagem aberta.

O entendimento de criança capaz de criar significado às suas experiências foi o fio condutor que guiou as vivências apresentadas. O papel do adulto acolhedor, disposto e atento a ouvir/sentir a comunicação da criança por meio da sua expressividade sensorial, promove singularidades dramáticas. $\mathrm{O}$ percurso investigativo vivenciado contribuiu para uma reflexão sobre os caminhos pedagógicos adotados na condução de processos artísticos, sobretudo, o papel do professor nas ações dramáticas.

Ao trabalhar o Drama na Educação Infantil, os dois conceitos apresentados nessa pesquisa foram explorados, acerca da atuação do professor no processo drama: Professor-personagem e Professor em ação dramática. Ao longo da vivência, as duas estratégias foram utilizadas simultaneamente, visto que no decurso das atividades permaneci todo o tempo como professora-personagem, no papel da palhaça, inclusive quando recorri a manipulação de bonecos de luva. A estratégia do Professor-personagem possibilitou-nos a pensar, pesquisar e construir uma personagem que dialogasse com as crianças e com o processo Drama em desenvolvimento. A atenção da turma foi obtida através do impacto visual causado pelo figurino e maquiagem, contribuindo para a proposição de novos desafios e/ou informações que impulsionaram o desenvolimento do processo criativo.

A estratégia do Professor em ação dramática foi utilizada concomitante com o Professorpersonagem, na medida em que me coloquei em um lugar de disposição para jogar com as crianças para assim estabelecer uma comunicação efetiva no processo Drama junto com elas. Nessa circunstância, foi possível compreender a possibilidade e o potencial da personagem Palhaça manipular os personagens bonecos, com intensa interação das crianças entre as duas realidades ficcionais.

Segundo Leite (2015) a proposta do Professor em ação dramática tem por objetivo a ampliação das possibilidades de comunicação entre professores e crianças pequenas, reividicando assim nessa comunicação o direito das crianças de se expressarem. Isto se dá através de um desenrolar de ações e reações que se estabelecem entre a criança e o professor criando uma espécie de jogo contínuo.

Nesse sentido, as duas propostas associadas, Professor-personagem e Professor em ação dramática, se relacionaram e se complementaram, em uma propensão para operarem interligados e interrelacionados. Desta maneira, as ações efetivadas estabeleceram uma relação com a criança, que ocasionou uma reação que por fim gerou uma ação. Diante dessa perspectiva, professor e criança são condutores e autores do processo dramático.

A partir desta experiência entendemos a importância e as implicações do corpo em movimento, no sentido de possibilitar as crianças e ao professor uma descoberta poética corporal. Nesse sentido, o professor que pouco prioriza o próprio corpo como potência para as atividades artísticas, permanece à 
margem do universo lúdico da criança e, por consequência, este profissional demonstra dificuldades para contribuir com a formação de corpos expressivos e comunicativos.

Tendo em vista os aspectos observados, a ação dramática com crianças pequenas acontece através de sutilezas, podendo ser realizada no cotidiano do espaço escolar, através das suas próprias ações, por meio do lúdico, do jogo, do faz de conta. Ao professor cabe a disponibilidade para perceber e acolher as propostas trazidas pelas crianças, para juntos atuarem como coautores do desenvolvimento criativo, da expressividade das ações dramáticas.

\section{Referências}

BRASIL. Ministério da Educação. Secretária de Educação Básica. Diretrizes curriculares nacionais para a educação infantil. Brasília: MEC, SEB, 2010.

CABRAL, Beatriz. Drama como método de ensino. São Paulo: Hucitec, 2012.

COURTNEY, Richard. Jogo, teatro e pensamento. São Paulo. Perspectiva, 2003.

LANDIER, Jean-Claude; BARRET, Gisèle. Expressão dramática e teatro. Porto: Edições ASA, 1994.

LARROSA, Jorge. Pedagogia Profana:danças, piruetas e mascaradas. Belo Horizonte: Autêntica, 2004.

LEITE. Elisângela Christiane de Pinheiro. Professor em Ação Dramática na Educação Infantil: Uma estratégia de comunicação entre professores e crianças pequenas.Jundiaí: Paco Editorial, 2015.

Domínio do Saber Epistêmico: Indutores utilizados pelo professor em ação dramática na relação com crianças da pequena infância. In: EDUCERE Congresso Nacional de Educação, XII, 2015. Curitiba. Anais...Formação de professores: contextos, sentidos e práticas. Curitiba: Editora Universitária Champagnat, 2015. p. 41003- 41015.

LEENHARDT, Pierre. A criança e a expressão dramática. São Paulo: Editora Estampa,1974.

PUPO, Maria Lúcia de Souza Barros. Para desembaraçar os fios. Educação e Sociedade. n.30, p. 217228, jul./dez., 2005.

SACRISTÁN, Gimeno J. Consciência e acção sobre a prática como libertação profissional dos professores. In: NÓVOA, Antônio (org.). Profissão Professor. 2.ed. Porto: Editora, 1999.

SAINT-EXUPÉRY, Antoine de. O Pequeno Príncipe. Rio de Janeiro: Agir, 2015.

SLADE, Peter. O Jogo Dramático Infantil. São Paulo: Summus, 1978.

VIDOR, Heloise Baurich. Drama e teatralidade: o ensino do teatro na escola. Porto Alegre: Mediação, 2010. 
